\title{
The Application of Vibration Accelerations in the Assessment of Average Friction Coefficient of a Railway Brake Disc
}

\author{
Wojciech Sawczuk \\ Poznan University of Technology, Institute of Combustion Engines and Transport, Faculty of Machines and Transport, pl. \\ M. Sklodowskiej-Curie 5,60-965 Poznan,Poland,wojciech.sawczuk@put.poznan.pl
}

\begin{abstract}
Due to their wide range of friction characteristics resulting from the application of different friction materials and good heat dissipation conditions, railway disc brakes have long replaced block brakes in many rail vehicles. A block brake still remains in use, however, in low speed cargo trains. The paper presents the assessment of the braking process through the analysis of vibrations generated by the components of the brake system during braking. It presents a possibility of a wider application of vibroacoustic diagnostics (VA), which aside from the assessment of technical conditions (wear of brake pads) also enables the determination of the changes of the average friction coefficient as a function of the braking onset speed. Vibration signals of XYZ were measured and analyzed. The analysis of the results has shown that there is a relation between the values of the point measures and the wear of the brake pads.
\end{abstract}

Keywords: Vibration, signal, diagnostic, railway disc brake, coefficient of friction.

\section{INTRODUCTION}

The growing speeds of trains force the application of friction disc brakes as the main train stopping systems. This is particularly the case for trains comprising a locomotive and passenger's coaches. In the case of traction sets, commonly referred to in Polish as 'EZT' a friction disc brake cooperates with an electrodynamic brake, in which the traction motors, acting as generators of additional resistance (regenerative braking) absorb the braking energy in the first stage of the process. Only in the second stage of braking are the disc brakes engaged at the speed of approx. $10 \mathrm{~km} / \mathrm{h}$ following the drop in the efficiency of the electrodynamic brake. Due to the use of two braking systems, the work on vibroacoustic diagnostics (VA) of traction motors is presented in the works [10], [11], [12] or friction discs described in the works [28], [30].

The main advantages of a disc brake system include a stable course of the average friction coefficient as a function of speed of the onset of braking on the level of 0.35 or 0.37 as per [17] depending on the maximum train speed ( 0.37 for $\mathrm{v}_{\max }=300 \mathrm{~km} / \mathrm{h}, \quad 0.35$ for $\mathrm{V}_{\max }=200 \mathrm{~km} / \mathrm{h}$ ) and $\operatorname{good}$ conditions of dissipation of the accumulated thermal energy to the environment, which is particularly efficient in the case of ventilated discs. A stable course of the braking process and the high value of average friction coefficient of as much as 0.4 , when sintered brake pads are applied, as well as a quick transfer and dissipation of thermal energy enables the application of greater forces of the brake pads exerted on the disc, hence better braking power.

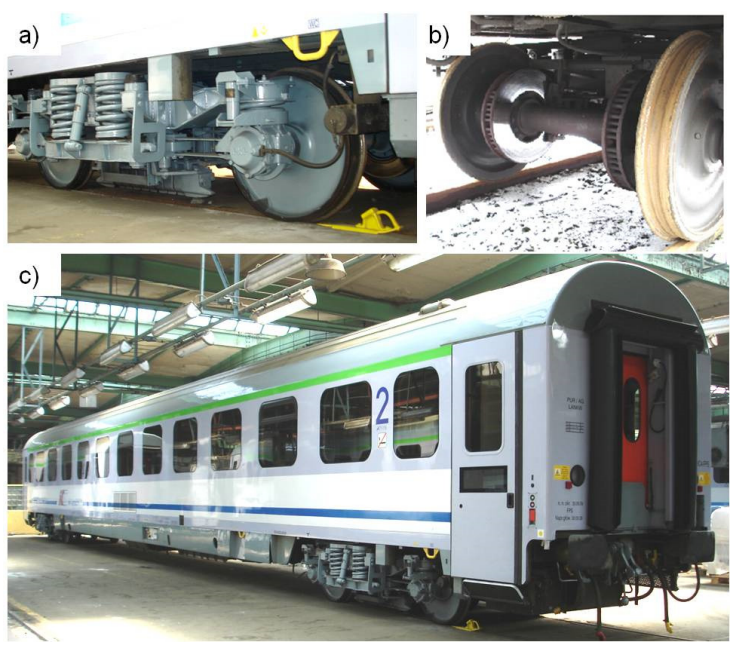

Fig.1. View of the passenger coach fitted with a disc brake: a) view of the MD 523 bogie, b) view of the wheelsets with the brake discs, c) view of the 136Amg passenger coach.

One of the few downsides of a disc brake system is that it is impossible to control the wear level of the components of the friction pair in operation. This is particularly conspicuous in passenger coaches, where the brake discs are fitted on the axles between the wheels as shown in Fig.1.b). In order to check the wear level of the friction pads, it is necessary to send the coach for service procedures so that the technicians can ascertain the wear from under the car and, if boundary wear is reached, renew the brake pads. In 
the automotive industry, the problem of brake pad wear has been resolved by applying a wear sensor in the brake pad. At the pad thickness of $2-3 \mathrm{~mm}$ the abrasion of the metal part of the sensor closes the circuit by connecting the sensor with the metal brake disc.

The selection of proper materials for the friction pair of a disc brake allows a wide range of the brake's friction characteristics, which directly influences the braking process. Instability of the braking process is an effect of a variety of phenomena discussed by many researchers. One of them is self-induced vibrations generated by the brake systems in different phases of the braking process, as presented in [7], [18], [27], [35]. The fluctuation of the instantaneous friction coefficient directly influences the vibration of variable amplitude. Another phenomenon of a thermal nature are the hot spots occurring on the brake disc, the effect of which is an uneven distribution of temperature and high local increments of temperature reaching 8 , presented in [36] as a relation between the maximum temperature (at the hot spot) of the friction ring and the minimum temperature. The problem of the hot spots phenomenon on both the brake discs and clutch discs in motor vehicles has been presented in [2], [14], [16], [19], [24]. A separate problem adversely influencing the braking process are the chemical changes occurring in the brake pad material at high temperatures (above $200^{\circ} \mathrm{C}$ ). This is related to the degassing of resins connecting the organic components of the metal brake pads, which results in the formation of a gas cushion between the brake pad and the disc. In literature, this effect is referred to as fading and has been described in [6], [8], [22]. In order to minimize the fading phenomenon, the manufacturers of the friction materials subject the brake pads to thermal processing at the temperature of $1200^{\circ} \mathrm{C}$ (scorching). Simultaneously, works are underway related to the materials for brake discs aiming at selecting appropriate components and thermal-chemical processing of irons, both gray and spheroid described in [1], [4], [5], [23], [25].

The aim of the investigations presented in the paper is an attempt to use the vibrations generated by the brake system while braking at different speeds to assess the braking process understood as change in the friction coefficient.

\section{SELECTED MODELS OF VIBRATIONS IN DISC BRAKES}

The initial models assumed that self-induced vibrations of the brake were related to the drop in the friction coefficient and an increase in the slide velocity. This is the case for a variety of materials but only for a limited range of speed change. If we assume a brake model of one degree of freedom as in Fig.2.b) then the equation of motion is expressed by the relation (1) [34].

$$
m \ddot{x}+c \dot{x}+k x+N\left(\mu_{s t}-\mu_{o}\right)
$$

\footnotetext{
where: $m_{1}, m_{2}-$ masses of bodies,

$N \quad-$ pressing force,

$k-\quad$ coefficient of resilience,

$c-$ coefficient of viscous damping,

$v_{o} \quad-$ velocity,
}

$\begin{array}{lll}\mu_{s t} & - & \text { coefficient of static friction, } \\ \mu_{o} & - & \text { coefficient of kinetic friction }\end{array}$ a)

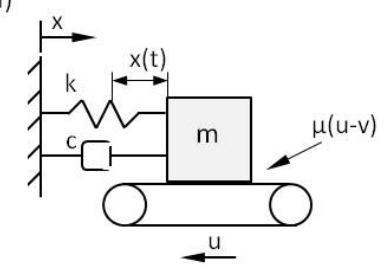

b)

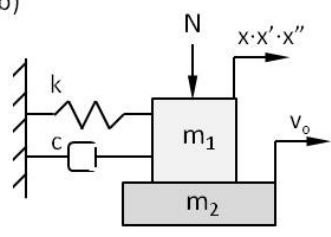

Fig.2. A model of vibrations of one degree of freedom: a) a model of a resilient friction system based on a conveyor; b) a model of mechanical system with feedback [34].

The system described in the equation of motion (1) will go into unstable vibrations depending on the values of the coefficient of damping $\mu$, as shown in the relation (2).

$$
c>\frac{N \Delta \mu}{2 \Pi \sqrt{k m v_{o}^{2}}}
$$

The first model that presents the possibility of instability of the friction system for a constant value of the friction coefficient was presented by Spurr as a slider with an angular support, as shown in Fig.3.a). This solution was improved by Jarvis and Earles. This mode, however, is geometrically inconsistent with the actual friction disc brake. Then, the condition of instability is determined with the relation (3) [34]:

$$
\frac{1}{2}(\mu-\operatorname{tg} \Theta \sin ) 2 \Theta>\frac{C_{p}}{C_{d}}
$$

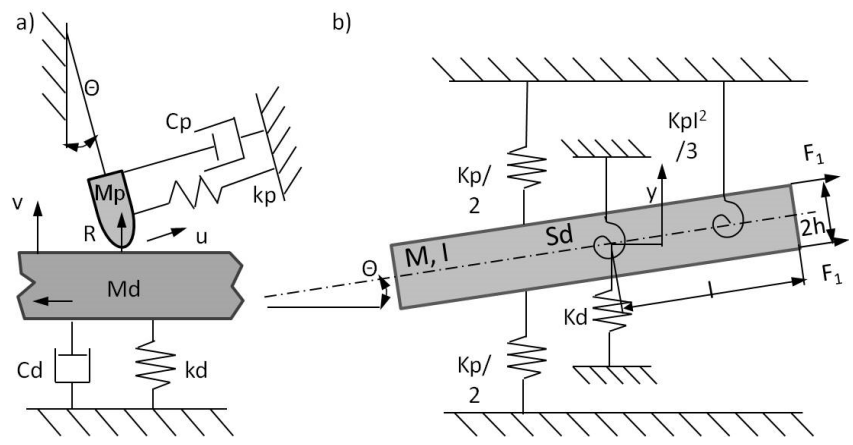

Fig.3. A model of instability of the friction system: a) disc - slider on an angular support; b) binary flutter of lumped parameters [34].

Another model was proposed by North and then Millner. This was a binary flutter model close to the model of a disc brake. The vibration mechanism in this case is similar to that of the fluttering effect of the wings of a plane. The race of the disc brake was replaced by a straight rigid beam of two degrees of freedom. The cross-section of the pad-race-pad system of the length of $2 x l$ is shown in Fig.3.b). The condition of instability of the presented model is expressed by the relation (4) [34]: 


$$
\frac{8 M I N \cdot \mu^{2} h}{\left(I-\frac{1}{3} M l^{2}\right)^{2}}>K_{p}>0
$$

$$
\text { where: } \begin{array}{ll}
2 h & - \text { thickness of the beam, } \\
M & - \text { mass, } \\
I & - \text { inertia, } \\
2 l & - \text { length of the beam, } \\
K p & - \text { transverse rigidity of the pad, } \\
K_{p} I^{2} / 3 & - \text { rotary rigidity for the } 21 \text { portion. }
\end{array}
$$

As Crolla and Lang have proved, this and the other models do not entirely reflect the actual brake operation. Thanks to these models, however, we can obtain qualitative information needed in the design process of brake systems and in the search for design solutions eliminating some classes of vibrations and the resultant noise [34].

\section{Methodology AND OBJeCt OF RESEARCH}

Research of a friction-vibroacoustic nature was performed on a certified inertia test stand at TABOR Institute of Rail Vehicles in Poznan. The test stand enables investigations of actual brake systems of rail vehicles (including pad and rail brakes) in the scale 1:1. Data obtained during tests on the certified brake inertia test stand are used for modeling the braking process or forecasting damage to brake system components. [9].

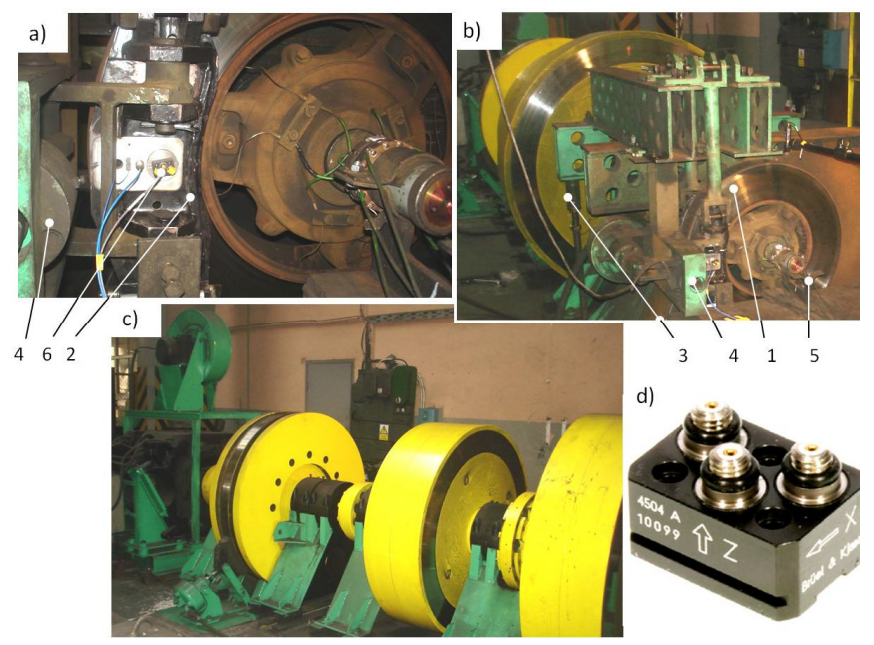

Fig.4. View of the research object on the disc brake test stand: a) view of the friction pair - brake disc and pads; b) View of the measurement section of the test stand; c) view of the drive component of the test stand with the rotating masses; d) View of the vibration transducer Brüel\&Kjær type 4504A, 1 - brake disc, 2 - brake clasps and the pads, 3 - static force sensor referred to the brake radius, 4 - sensors of the pressing force of the pads to the brake disc, 5 - rotational speed sensor, 6 - vibration transducer.

The investigations were performed according to the assumptions of the active experiment described in [20], [21], the input parameters were intentionally modified in order to record the output parameters. The input parameters were the simulated speed of the onset of braking $v$, the pressing force of the pads on the brake disc $N$, the mass to be decelerated $M$, and the wear of the brake pads $G$. The output parameters were instantaneous tangential force $F_{t}$ referred to the radius of braking $r$, instantaneous pressing force on the brake disc $F_{b}$, and instantaneous value of the vibration accelerations $a$. The observations of the input parameters on the changes of the output parameters were performed.

Fig.4. presents the brake test stand and the measurement equipment. For the measurements, the following sensors have been applied: HBM sensors (force) and $B \& K$ transducers (vibrations). The research object was a $590 \times 110$ railway brake disc with ventilating vanes and three sets of 175 FR20H.2 brake pads (a set of new pads of the thickness of $35 \mathrm{~mm}$ and two worn sets of $25 \mathrm{~mm}$ and $15 \mathrm{~mm}$ ). During the tests a procedure of active experiment was applied, in which the output parameters were recorded following a modification of the input parameters.

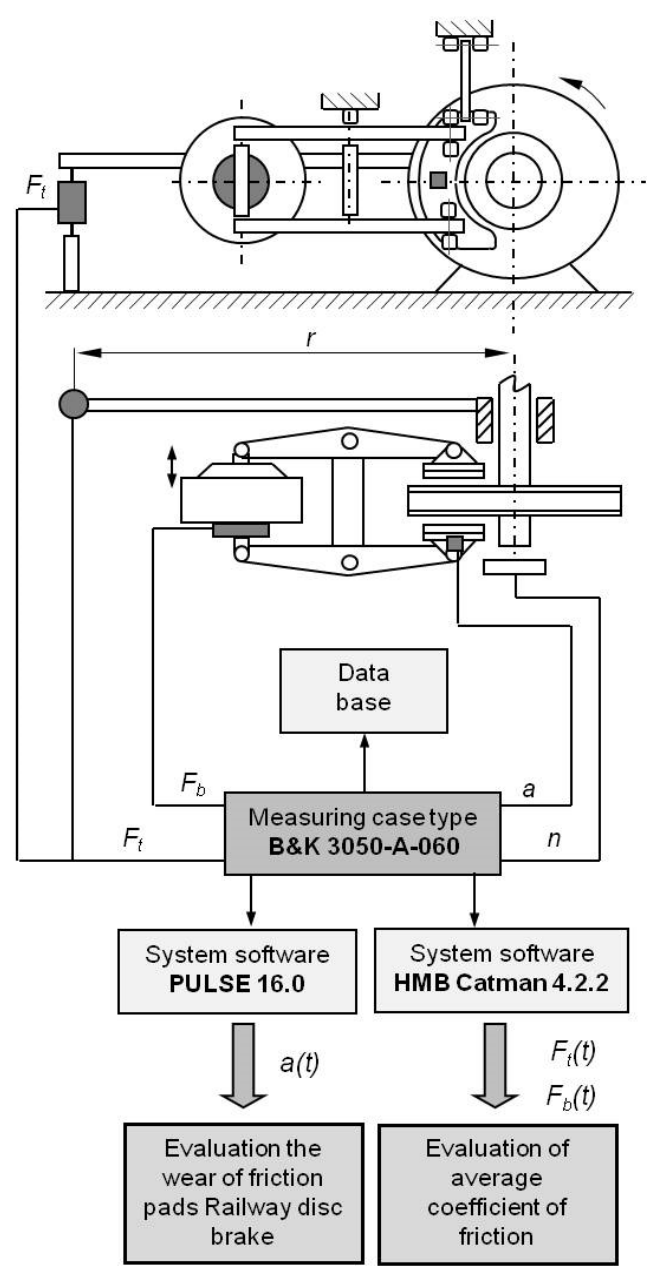

Fig.5. Diagram of the measurement track used in the investigations.

Tests of a tribological nature were performed according to the requirements stipulated in [17], [26]. During the tests, braking was performed from the speeds of 50, 80, 120, 160 and $200 \mathrm{~km} / \mathrm{h}$. During the tests, the pressing force of the pads to the disc of $25 \mathrm{kN}$ was applied and the simulated mass to be decelerated was 5.7 tons. 
The vibroacoustic tests were performed simultaneously with the friction (tribological) tests. One of the clasps was fitted with the vibration transducer shown in Fig.4.a). The measurements of the vibration accelerations were performed perpendicularly to the surface of the disc based on the experience of other researchers presented in [28], [32]. Fig.5. presents the diagram of the measurement track on the test stand additionally extended by the measurement of the vibration accelerations.

\section{ANALYSIS OF THE RESULTS}

In the domain of amplitudes of the analysis of vibration accelerations, the most frequently used are point measures that characterize a given vibration process with a single value according to [37]. Then, in vibroacoustic diagnostics in particular (VA), it is possible to determine the changes in the VA signal that result from a change of the technical condition of the tested object. Literature presents a variety of papers depicting the application of vibroacoustic diagnostics in road vehicles, rail vehicles, and aircrafts [3], [32], [33]. In order to determine the relation between the average friction coefficient and the vibrations generated by the brake system, in the first place it was proved that there exists a relation between the vibrations measured on the clasp and the technical condition of the system understood as the wear of the brake pads. To this end, for all analyzed speeds on the test stand, vibrations of the clasp were recorded, as shown in Fig.6. Then the following point measures were determined according to [37]:

1) RMS value of the vibration accelerations described with the relation (5):

$$
A_{R M S}=\sqrt{\frac{1}{T} \int_{0}^{T}[a(t)]^{2} d t}
$$

where: $T-$ averaging time in [s],

$a(t) \quad-\quad$ instantaneous value of the vibration accelerations in $\left[\mathrm{m} / \mathrm{s}^{2}\right]$.

2) The average values of the vibration accelerations described with the relation (6):

$$
A_{A V E R A G E}=\frac{1}{T} \int_{0}^{t}|a(t)| d t
$$

3) Root value of the vibration acceleration described with the relation (7):

$$
A_{\text {SQUARE }}=\left[\frac{1}{T} \int_{0}^{T}|a(t)| \frac{1}{2} d t\right]^{2}
$$

4) Peak value of the vibration accelerations described with the relation (8):

$$
A_{P E A K}=\left[\frac{1}{T} \int_{0}^{T}|s(t)|^{\infty} d t\right]^{\frac{1}{n}} d l a n \rightarrow \infty
$$
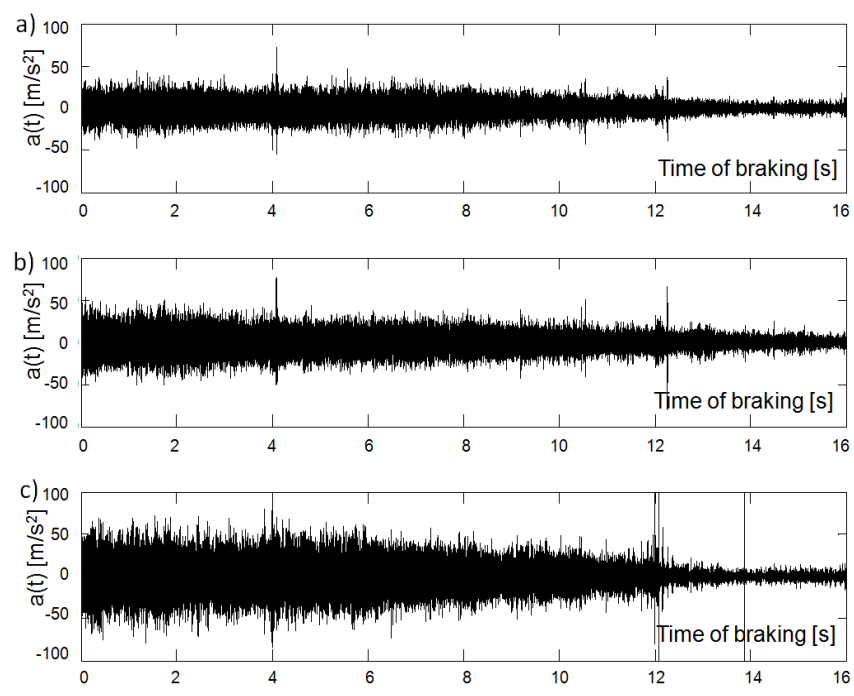

Fig.6. Instantaneous value of the vibration accelerations of the brake clasp with the brake pads when braking from the speed of 120 to the speed of $90 \mathrm{~km} / \mathrm{h}$ with: a) new pads G1=35 mm; b) pads worn to $25 \mathrm{~mm}$; c) pads worn to $15 \mathrm{~mm}$.

For each point measure, the potential of using it as a parameter indicating the condition of the brake pads was verified. To this end, the coefficient of dynamics of the change of the diagnostic parameter was applied as per the relation (9) [13]:

$$
D=20 \lg \left(\frac{A_{2}}{A_{1}}\right)
$$

where: $A_{1}$ - value of the point measure ( $A_{R M S}$ or $\left.A_{A V E R A G E}\right)$ determined when braking with new brake pads, $\mathrm{G} 1=35 \mathrm{~mm} \mathrm{w}\left[\mathrm{m} / \mathrm{s}^{2}\right]$,

$A_{2}$ - value of the point measure (ARMS or $A_{A V E R A G E}$ ) determined when braking with used brake pads, $\mathrm{G} 2=25$ and $\mathrm{G} 3=15 \mathrm{~mm} \mathrm{w}\left[\mathrm{m} / \mathrm{s}^{2}\right]$.

The recorded vibration signals were analyzed in Matlab 2014a. This included a deletion of fragments of signals not related to the braking process (startup of the test stand and coasting needed for the disc cooling), averaging as per relations (5)-(8) and determining of the dynamics of the change of the diagnostic parameter.

Table 1. presents the values of the point measures determined in the braking process for different speeds of the onset of braking.

The analysis of the results has shown that there is a relation between the values of the point measures and the wear of the brake pads (measuring the vibrations on the clasps with the brake pads fitted). Only in the case of low braking onset speeds (to $50 \mathrm{~km} / \mathrm{h}$ ) the dynamics of changes of the most heavily worn brake pad $(15 \mathrm{~mm})$ does not reach 
$6 \mathrm{~dB}$. The braking processes for the speed starting from $80 \mathrm{~km} / \mathrm{h}$ result in the peak value of the vibration acceleration and dynamics of the changes of the diagnostic parameter exceeding $6 \mathrm{~dB}$. Higher braking onset speeds (160 and 200 $\mathrm{km} / \mathrm{h}$ ) cause also this point measure $\left(A_{P E A K}\right)$ to find application in the measurements of the brake system vibrations.

Table 1. Values of the point measures for the braking process leading to a complete halt.

\begin{tabular}{|c|c|c|c|c|c|}
\hline \multirow[b]{2}{*}{$\begin{array}{c}\text { Point } \\
\text { measure }\end{array}$} & \multicolumn{3}{|c|}{$\begin{array}{l}\text { Value of the point measure in } \\
\qquad \mathrm{m} / \mathrm{s}^{2}\end{array}$} & \multicolumn{2}{|c|}{$\begin{array}{l}\text { Dynamics } \\
\text { of changes } \\
\text { in } \mathrm{dB}\end{array}$} \\
\hline & $\begin{array}{l}\text { Brake pad } \\
\text { of the } \\
\text { thickness of } \\
\mathrm{G} 1=35 \mathrm{~mm}\end{array}$ & $\begin{array}{l}\text { Brake pad } \\
\text { of the } \\
\text { thickness } \\
\text { of } \mathrm{G} 2=25 \\
\mathrm{~mm}\end{array}$ & $\begin{array}{c}\text { Brake pad } \\
\text { of the } \\
\text { thickness } \\
\text { of } \mathrm{G} 3=15 \\
\mathrm{~mm}\end{array}$ & $\begin{array}{l}\text { G2/ } \\
\text { G1 }\end{array}$ & $\begin{array}{l}\text { G3/ } \\
\text { G1 }\end{array}$ \\
\hline \multicolumn{6}{|c|}{ Speed of the onset of braking $\mathrm{v}=50 \mathrm{~km} / \mathrm{h}$} \\
\hline $\mathrm{A}_{\mathrm{RMS}}$ & 6.88 & 9.36 & 10.63 & 2.67 & 3.78 \\
\hline A AVERAGE & 5.18 & 7.01 & 8.07 & 2.63 & 3.86 \\
\hline AsQuARE & 4.25 & 6.26 & 6.88 & 3.35 & 4.17 \\
\hline APEAK & 45.06 & 59.25 & 65.35 & 2.38 & 3.23 \\
\hline \multicolumn{6}{|c|}{ Speed of the onset of braking $\mathrm{v}=80 \mathrm{~km} / \mathrm{h}$} \\
\hline ARMS & 7.29 & 12.47 & 15.05 & 4.66 & 6.29 \\
\hline AAVERAGE & 5.55 & 9.39 & 11.48 & 4.57 & 6.32 \\
\hline AsQuARE & 11.10 & 20.44 & 25.06 & 5.30 & 7.08 \\
\hline APEAK & 52.57 & 71.69 & 90.75 & 2.69 & 4.74 \\
\hline \multicolumn{6}{|c|}{ Speed of the onset of braking $\mathrm{v}=120 \mathrm{~km} / \mathrm{h}$} \\
\hline$A_{\text {RMS }}$ & 8.65 & 13.95 & 17.68 & 4.15 & 6.21 \\
\hline A AVERAGE & 6.61 & 10.62 & 13.60 & 4.12 & 6.26 \\
\hline AsQuARE & 28.66 & 53.51 & 68.67 & 5.42 & 7.59 \\
\hline APEAK & 59.63 & 95.22 & 111.55 & 4.07 & 5.44 \\
\hline \multicolumn{6}{|c|}{ Speed of the onset of braking $\mathrm{v}=160 \mathrm{~km} / \mathrm{h}$} \\
\hline ARMS & 10.03 & 14.17 & 37.46 & 3.00 & 11.4 \\
\hline A AVERAGE & 7.59 & 10.67 & 18.66 & 2.96 & 7.8 \\
\hline AsQuARE & 62.34 & 106.42 & 168.47 & 4.64 & 8.6 \\
\hline APEAK & 77.05 & 124.80 & 471.50 & 4.19 & 15.7 \\
\hline \multicolumn{6}{|c|}{ Speed of the onset of braking $v=200 \mathrm{~km} / \mathrm{h}$} \\
\hline $\mathrm{A}_{\mathrm{RMS}}$ & 9.68 & 12.57 & 96.31 & 2.27 & 19.7 \\
\hline Aaverage & 7.40 & 9.59 & 39.12 & 2.26 & 14.5 \\
\hline AsQuARE & 104.5 & 179.86 & 493.99 & 4.72 & 13.5 \\
\hline APEAK & 85.20 & 131.30 & 918.63 & 3.76 & 20.6 \\
\hline
\end{tabular}

Fig.7. presents a graphical relation between the analyzed point measures and the braking onset speeds, i.e. 50, 80, 120, 160 and $200 \mathrm{~km} / \mathrm{h}$. Fig. 8 . shows the relation between the dynamics of changes of the diagnostic parameter and the analyzed braking onset speeds. Following the information in Table 1., Fig.7. and Fig.8., it has been confirmed that the difference in the values of the point measures (between the new brake pads and the used ones) increases with the growing braking onset speed. Due to the dynamic nature of the braking process, particularly at high braking onset speeds, the vibrations generated by the brake system provide information related to the wear of the brake pads, which, in the further part of the paper will also be used in the assessment of the braking process understood as changes in the average friction coefficient.
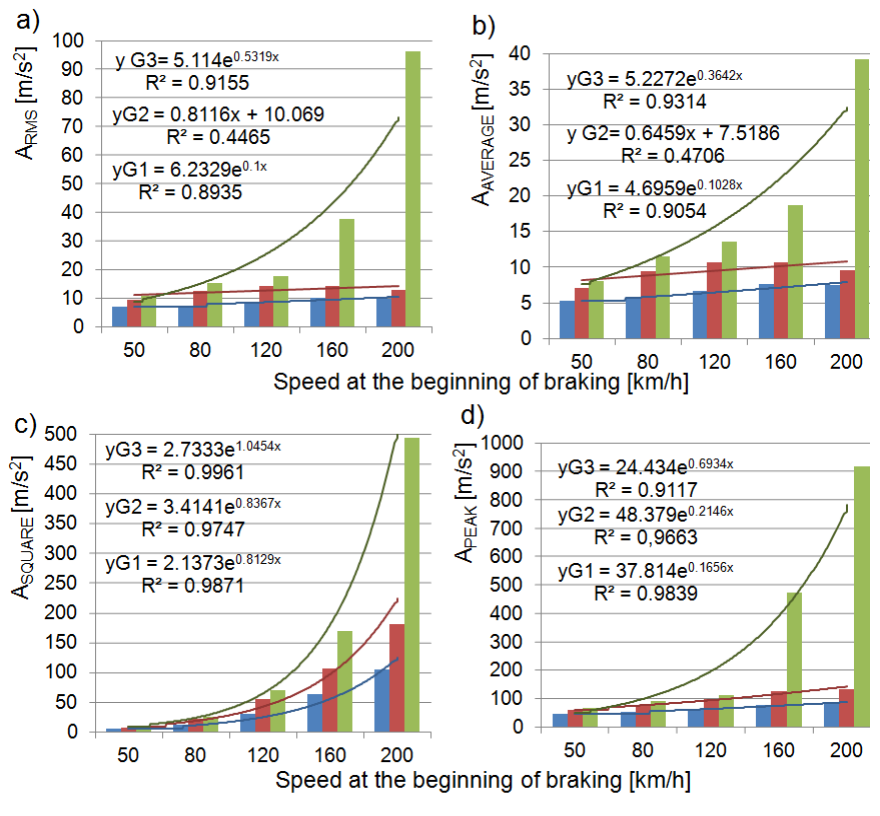

d)

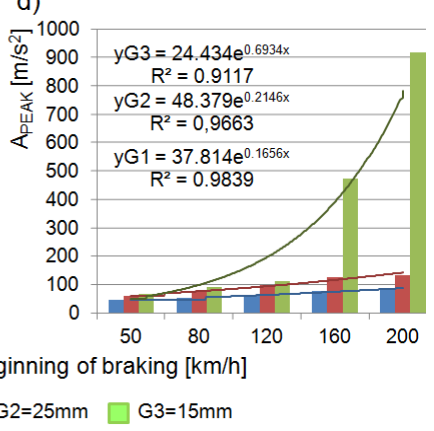

Fig.7. The relation of the values of selected point measures of vibration accelerations for three values of the brake pad thickness as a function of the braking onset speed: a) RMS value; b) average value; c) root value; d) peak value.

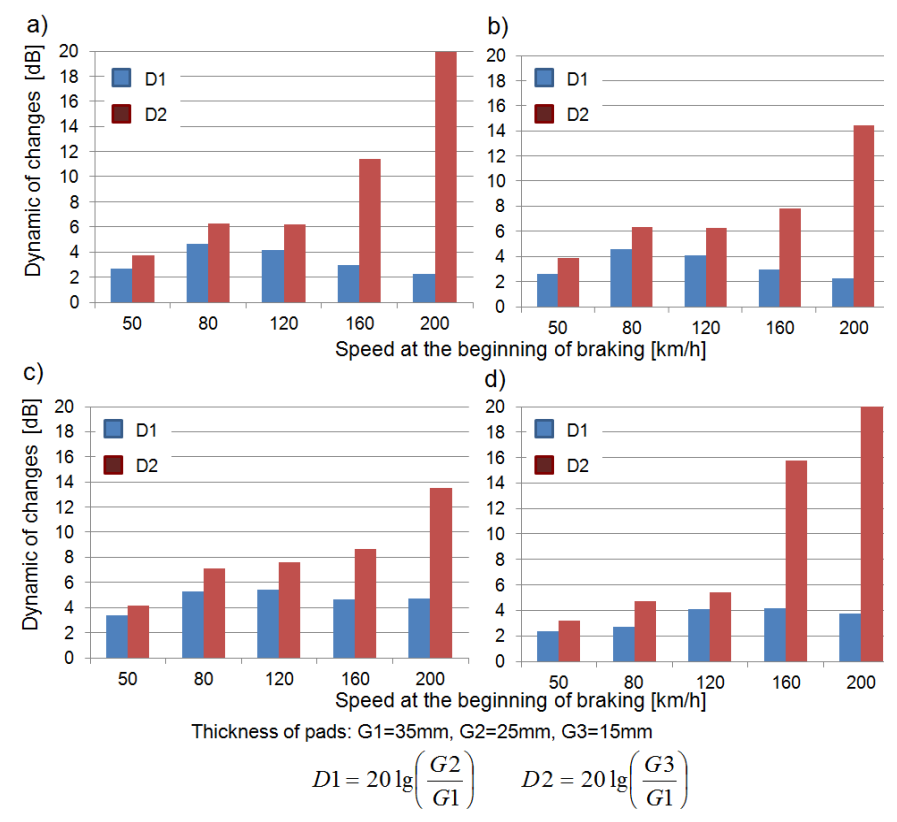

Fig.8. The relation of the dynamics of changes for selected point measures of vibration accelerations for three values of the brake pad thickness as a function of the braking onset speed: a) RMS value; b) average value; c) root value; d) peak value.

For further analyses, the effective and the average values of the vibration accelerations from the point measures were utilized due to the high value of the coefficient of dynamics of the changes of the diagnostic parameter for all braking onset speeds under analysis. In order to assess the brake pad wear, a reverse function to the approximating functions (shown in Fig.7.) was applied, so that it was possible to 
assess the thickness of the brake pads based on the value of the point measures, averaging the entire process of braking until a full halt.

Fig.9. and Fig.10. show the relation between the brake pad thickness and a given point measure, i.e. the effective value and the average value.

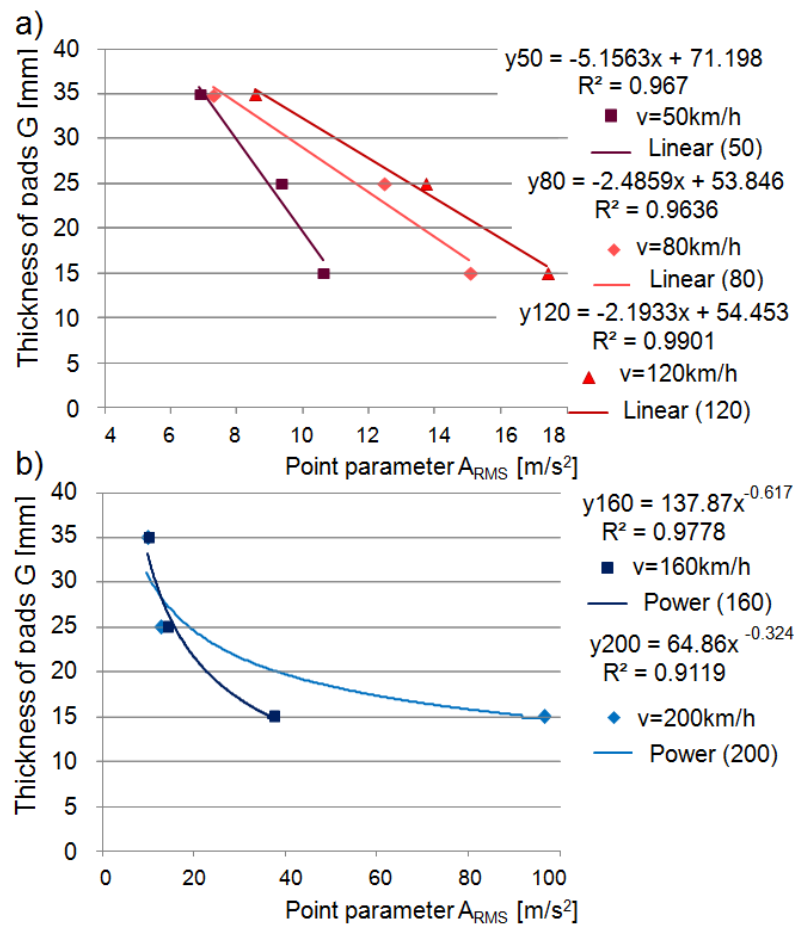

Fig.9. Dependence of the brake pad thickness on the RMS value of the vibration acceleration for the braking onset speeds of: a) $v=50$, 80 and $120 \mathrm{~km} / \mathrm{h}$; b) v=160 and $200 \mathrm{~km} / \mathrm{h}$.

The dependence of the brake pad thickness on the values of the point measures, due to the highest value of the coefficient of determinance $R^{2}$, was approximated with linear functions for the braking onset speeds from 50 to $120 \mathrm{~km} / \mathrm{h}$ and exponential functions for the speeds of 160 and $200 \mathrm{~km} / \mathrm{h}$, which is expressed by the relations (10)-(19):

$$
\begin{aligned}
& G_{(v=50)}=-5.1 \cdot A_{R M S}(v=50)+71.2 \\
& G_{(v=80)}=-2.5 \cdot A_{R M S}(v=80)+53.8 \\
& G_{(v=120)}=-2.2 \cdot A_{R M S}(v=120) \\
& G_{(v=160)}=137.9 \cdot A_{R M S(v=160)} \\
& G_{(v=200)}=64.617 \\
& G_{(v=50)}=-6.7 \cdot A_{\text {AVERS }(v=200)}-0.324 \\
& G_{(v=80)}=-3.3 \cdot A_{\text {AVERAGE }(v=50)}+70.6
\end{aligned}
$$

$$
\begin{gathered}
G_{(v=120)}=-2.8 \cdot A_{A V E R A G E}(v=120)+54.2 \\
G_{(v=160)}=233.7 \cdot A_{A V E R A G E}(v=160)^{-0.94} \\
G_{(v=200)}=79.6 \cdot A_{A V E R A G E}(v=200)
\end{gathered}
$$

In the further stage of the investigations carried out simultaneously with the vibration research, the authors measured instantaneous tangential force $F_{t}$ referred to the braking radius and the instantaneous clamping force $F_{b}$ of the friction pads to the brake disc in order to calculate the friction coefficient according to the relation (20) [17]:

$$
\mu_{a}=\frac{F_{t}}{F_{b}}
$$

Then, the average friction coefficient for all braking onset speeds under analysis was calculated as an integral of the instantaneous friction coefficient on the braking distance $s_{2}$ as per the relation (21) [17]:

$$
\mu_{m}=\frac{1}{s_{2}} \int_{0}^{s_{2}} \mu \cdot d s
$$

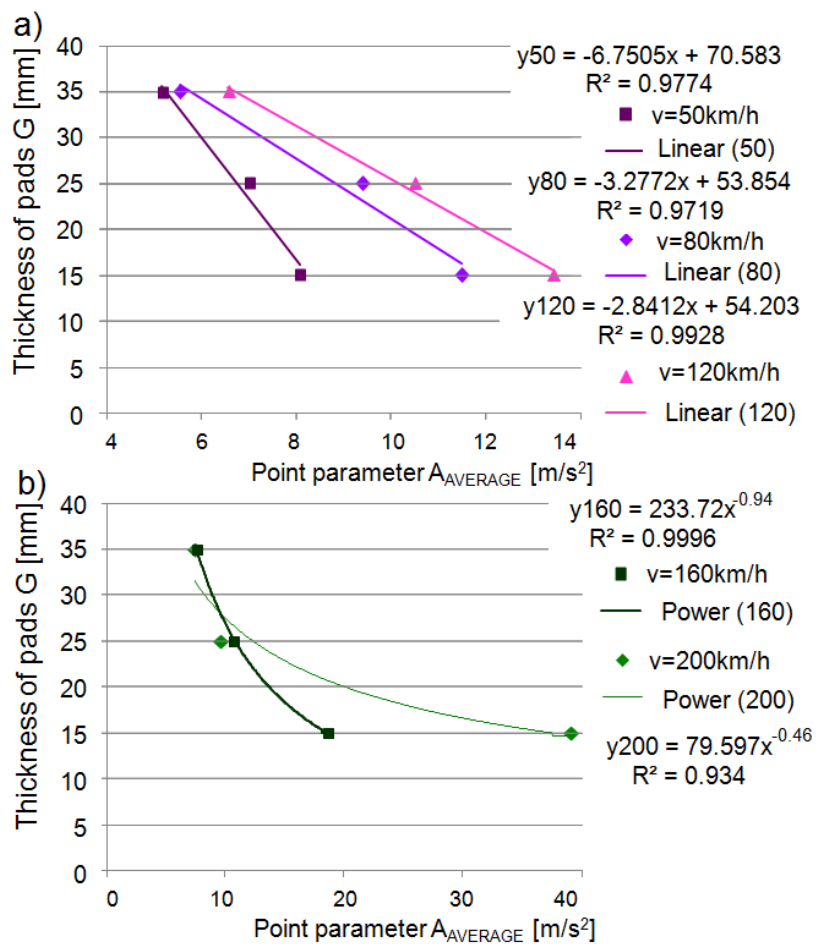

Fig.10. Dependence of the brake pad thickness on the average value of the vibration acceleration for the braking onset speeds of: a) $\mathrm{v}=50,80$ and $120 \mathrm{~km} / \mathrm{h}$; b) $\mathrm{v}=160$ and $200 \mathrm{~km} / \mathrm{h}$.

Fig.11. shows the average friction coefficient as a function of the braking onset speed for three values of the brake pad thickness. 


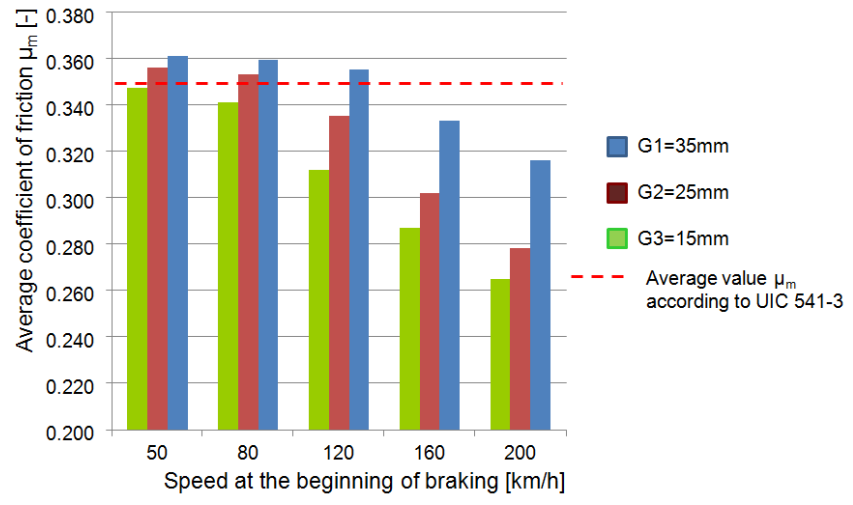

Fig.11. Dependence of the average friction coefficient $\mu_{m}$ on the braking onset speed at $\mathrm{N}=25 \mathrm{kN}, \mathrm{M}=5.7 \mathrm{t}$ for three values of the brake pad thickness.

Analyzing Fig.11., it can also be observed that the average friction coefficient also depends on the conditions of the brake pads (their wear). As the brake pads wear down, the value of the average friction coefficient decreases. Fig.12. and Fig.13. show the dependence of $\mu_{m}$ on the thickness of the brake pads. Additionally, the average friction coefficient was approximated with the linear function as shown by the relations presented in the graphs.

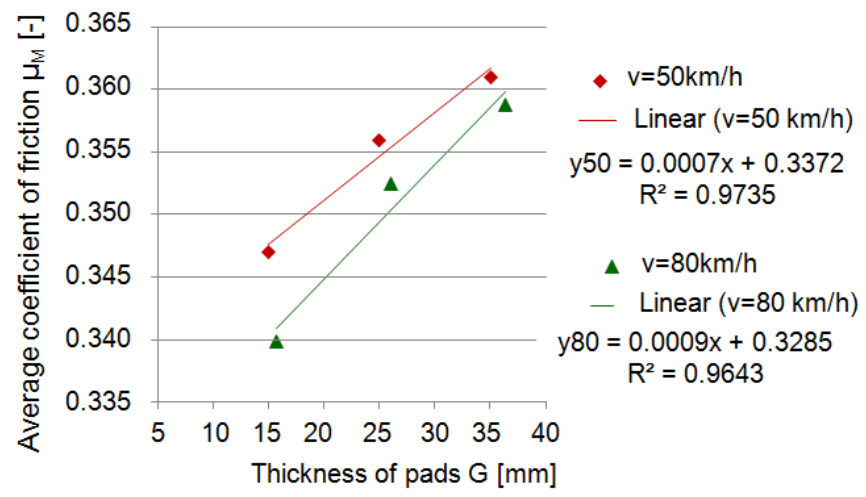

Fig.12. Dependence of the average friction coefficient $\mu_{m}$ on the thickness of the brake pads for the braking onset speeds of $\mathrm{v}=50$ and $80 \mathrm{~km} / \mathrm{h}$.

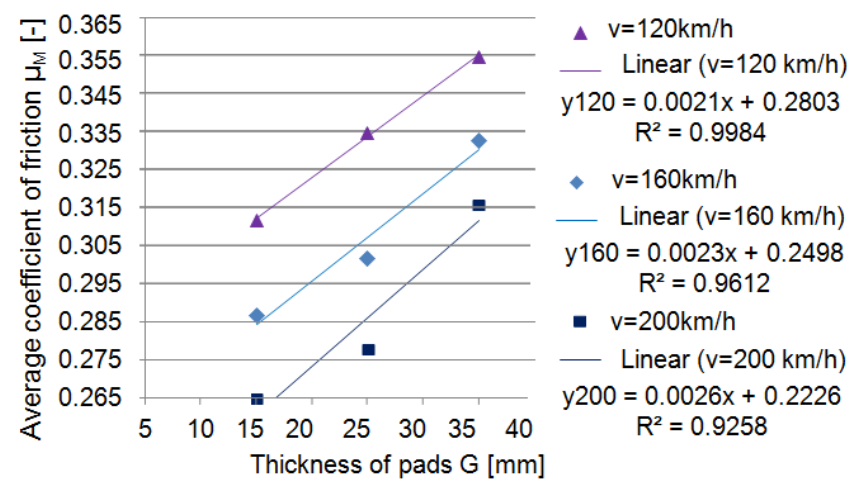

Fig.13. Dependence of the average friction coefficient $\mu_{m}$ on the thickness of the brake pads for the braking onset speeds of $\mathrm{v}=120$, 160 and $200 \mathrm{~km} / \mathrm{h}$.
Because of the occurrence of linear (low braking onset speeds) or non-linear (higher braking onset speeds) relation between the values of the brake pad thickness and the values of the point measures and a linear relation between the average friction coefficient and the brake pad thickness, a relation aiming at the estimation of the average friction coefficient based on the recorded vibrations was determined through the method of substitution of two functions. A general form of the determination of the average value of the friction coefficient is expressed by equations (22) and (23). Equation (22) is based on two linear functions and equation (23) is a result of joining a non-linear function with a linear one.

$$
\begin{aligned}
& \left\{\begin{array}{l}
G=a_{1} A_{R M S}\left(\text { or } A_{A V E R A G E}\right)+b_{1} \\
\mu_{m}=a_{a} G+b_{2}
\end{array}\right. \\
& \mu_{m}=a_{1} a_{2} A_{R M S}\left(\text { or } A_{A V E R A G E}\right)+a_{2} b_{1}+b_{2} \\
& \text { for } v=50,80,120\left[\frac{\mathrm{km}}{\mathrm{h}}\right] \\
& \left\{\begin{array}{l}
G=a_{1} A_{R M S}\left(\text { or } A_{A V E R A G E}\right)^{b_{1}} \\
\mu_{m}=a_{a} G+b_{2}
\end{array}\right. \\
& \mu_{m}=a_{1} a_{2} A_{R M S}\left(\text { or } A_{A V E R A G E}\right)^{b_{1}}+b_{2} \\
& \text { for } v=160,200\left[\frac{\mathrm{km}}{\mathrm{h}}\right]
\end{aligned}
$$

Applying the relations pertaining to the brake pad wear as a function of the values of the point measures of the vibration accelerations and between the average friction coefficient and the brake pad wear based on the assumptions of functions (22) and (23), the following relations for the assessment of the average friction coefficient were determined:

$$
\begin{gathered}
\mu_{m,(v=50)}=-0.0036 \cdot A_{R M S(v=50)}+0.387 \\
\mu_{m,(v=80)}=-0.0022 \cdot A_{R M S(v=80)}+0.376 \\
\mu_{m,(v=120)}=-0.0046 \cdot A_{R M S(v=120)}+0.394 \\
\mu_{m,(v=160)}=0.331 \cdot A_{R M S(v=160)}-0.617+0.249 \\
\mu_{m,(v=200)}=0.168 \cdot A_{R M S(v=200)^{-0.324}+0.222} \\
\mu_{m,(v=50)}=-0.0047 \cdot A_{A V E R A G E(v=50)}+0.386 \\
\mu_{m,(v=80)}=-0.0029 \cdot A_{A V E R A G E(v=80)}+0.376 \\
\mu_{m,(v=120)}=-0.0059 \cdot A_{A V E R A G E(v=120)}+0.394 \\
\mu_{m,(v=160)}=0.56 \cdot A_{A V E R A G E(v=160)}^{-0.94}+0.249
\end{gathered}
$$




$$
\mu_{m,(v=200)}=0.21 \cdot A_{A V E R A G E}(v=200)^{-0.46}+0.222
$$

where: $\quad \mu_{m}-$ average value of the friction coefficient [-], $A_{2}$ - value of the effective point $A_{R M S}$ or average $A_{A V E R A G E}$ measure in $\left[\mathrm{m} / \mathrm{s}^{2}\right]$.

The analyses of the results in the domain of amplitudes have shown that, based on the point measures of vibration accelerations of the brake system discussed in the paper, a diagnostic of the brake conditions is possible as described earlier in [15], [28], [31], including the assessment of the braking process through the determination of the average friction coefficient. Table 2 . and Table 3 . present the relative percentage error of the suitability of the model of the average friction coefficient based on functions (23)-(32) against the values determined during the tests on a certified railway brake test stand. The authors relied on the two point measures of the vibration accelerations measured on the brake clasps during the braking process. It should be noted that also in the field of vibroacoustic diagnostics of the braking systems are used more advanced analyses as frequency analysis presented in the work [29] or timefrequency analysis [30]. However, in spite of the greater accuracy of the friction wear estimation, in the case of a diagnostic system, such analyses will generate a more sophisticated vibroacoustic signal processing system.

Table 2. Relative percentage error of the suitability of the model of the average friction coefficient to the test results based on the determined effective values $A_{R M S}$ of the vibration accelerations.

\begin{tabular}{|c|c|c|c|}
\hline \multicolumn{5}{|c|}{ For the point measure $A_{R M S}$} \\
\hline Speed $[\mathrm{km} / \mathrm{h}]$ & $\begin{array}{l}\text { For a new } \\
\text { brake pad G1 }\end{array}$ & $\begin{array}{l}\text { For the worn } \\
\text { brake pad G2 }\end{array}$ & $\begin{array}{l}\text { For the worn } \\
\text { brake pad G3 }\end{array}$ \\
\hline $\mathrm{v}=50$ & 0.3 & 0.8 & 0.5 \\
\hline $\mathrm{v}=80$ & 0.3 & 1.3 & 0.6 \\
\hline $\mathrm{v}=120$ & 0.2 & 1.5 & 0.2 \\
\hline $\mathrm{v}=160$ & 1.3 & 3.7 & 0.9 \\
\hline $\mathrm{v}=200$ & 4.3 & 6.1 & 1.8 \\
\hline
\end{tabular}

Table 3. Relative percentage error of the suitability of the model of the average friction coefficient to the test results based on the determined average values $A_{A V E R A G E}$ of the vibration accelerations.

\begin{tabular}{|c|c|c|c|}
\hline \multicolumn{5}{|c|}{ For the point measure $A_{A V E R A G E}$} \\
\hline Speed $[\mathrm{km} / \mathrm{h}]$ & $\begin{array}{l}\text { For a new } \\
\text { brake pad G1 }\end{array}$ & $\begin{array}{l}\text { For the worn } \\
\text { brake pad G2 }\end{array}$ & $\begin{array}{l}\text { For the worn } \\
\text { brake pad G3 }\end{array}$ \\
\hline $\mathrm{v}=50$ & 0.2 & 0.8 & 0.3 \\
\hline $\mathrm{v}=80$ & 0.3 & 1.2 & 0.5 \\
\hline $\mathrm{v}=120$ & 0 & 1.1 & 0.6 \\
\hline $\mathrm{v}=160$ & 0.2 & 2.4 & 0.8 \\
\hline $\mathrm{v}=200$ & 3.3 & 6.2 & 1.6 \\
\hline
\end{tabular}

The graphical representation of the suitability of the regressive model of the value estimation of the average friction coefficient against the test results on the railway brake test stand is shown in Fig. 14.

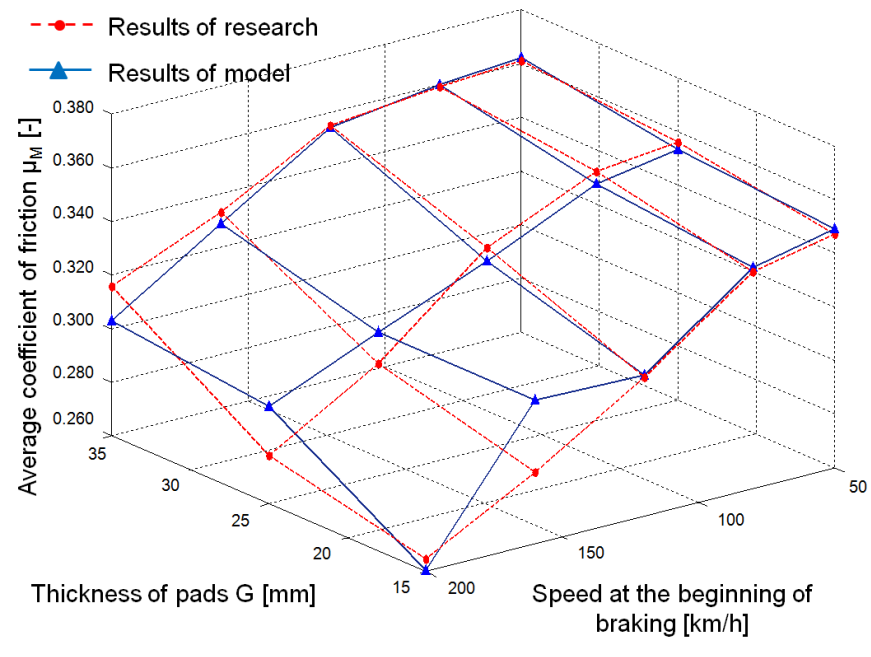

Fig.14. Relation between the average friction coefficient $\mu_{m}$ obtained during the investigations and the regressive model obtained from equations (23)-(32) as a function of the thickness of the brake pads and the braking onset speeds.

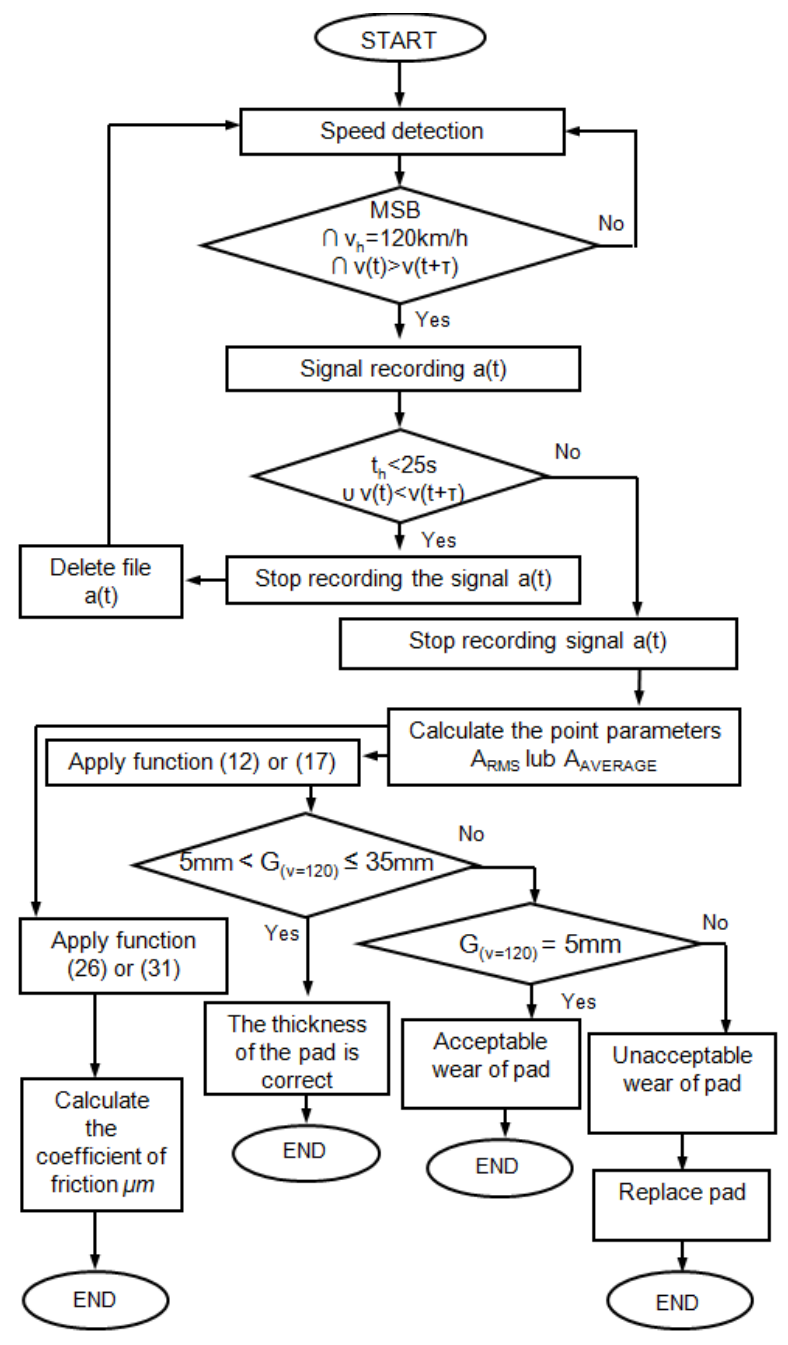

Fig.15. Algorithm for evaluation of wear of friction pads and assessment of braking process on example of braking from speed $\mathrm{v}=120 \mathrm{~km} / \mathrm{h}$, MSB - Make stopping braking, $\tau$ - time increment. 
Fig.15. shows the algorithm for the selected braking speed for simultaneous evaluation of friction pad wear and the evaluation of braking. The braking process is evaluated by determining the mean friction coefficient. The algorithm used to process the vibroacoustic signal generated by the friction pad during braking is used to assess friction wear. The wear assessment is made in three ranges, i.e. for the thickness of the pad between 5 and $35 \mathrm{~mm}$, for a thickness of $5 \mathrm{~mm}$, and for a thickness of less than $5 \mathrm{~mm}$ where a pad replacement message is generated for the new pad. Then, by applying the functions described in (24) - (33), it is possible to determine the mean coefficient of friction for the braking speed from 50 to $200 \mathrm{~km} / \mathrm{h}$.

\section{CONCLUSION}

The paper presents a possibility of a wider application of vibroacoustic diagnostics (VA), which, aside from the assessment of technical conditions (in this case, wear of the brake pads) also enables the determination of the changes of the average friction coefficient as a function of the braking onset speed. It results from the fact of a heavy dependence of the diagnostic parameter on the brake pad wear expressed with the dynamics of changes exceeding $6 \mathrm{~dB}$ as well as the dependence of the average friction coefficient on the speed and brake pad wear. The connection of both functions, i.e. the wear of the brake pads/values of the point measures of vibration accelerations and the average friction coefficient/wear of the brake pads allows determining the linear (low speeds) and non-linear (greater speeds) regressive models for the assessment of the average friction coefficient. In the analysis of vibration signals, point measures in the domain of amplitudes are sufficient being averaged to a single value of instantaneous changes of the vibration accelerations of a selected component of a brake system. An error in the reproduction of the model of average friction coefficient, based on the determined point measures during the braking process, reaches $6 \%$ only for some braking onset speeds. The article presents an algorithm for simultaneous evaluation of wear of friction pads and evaluation of braking process based on linear functions (24)(33). The application of more sophisticated analysis tools such as FFT and STFT frequency analysis with filters or the application of a time-frequency analysis will enable better compliance of the model results with the actual results, however, it will result in a more complicated signal processing system and ultimately a more complex diagnostic system.

\section{ACKNOWLEDGMENTS}

The project has been financed by the National Centre for Research and Development, program LIDER V, contract No. LIDER/022/359/L-5/13/NCBR/2014

\section{REFERENCES}

[1] Aranganathan, N., Bijwe, J. (2016). Development of copper-free eco-friendly brake-friction material using novel ingredients. Wear, 352-353, 79-91.
[2] Belhocine, A., Bouchetara, M. (2012). Thermomechanical modelling of dry contacts in automotive disc brake. International Journal of Thermal Sciences, 60, 161-170.

[3] Chen, J., Randall, R.B., Peeters, B. (2016). Advanced diagnostic system for piston slap faults in IC engines, based on the non-stationary characteristics of the vibration signal. Mechanical System and Signal Processing, 75, 434-454.

[4] Collignon, M., Regheere, G., Cristol, A.L., Desplanques, Y., Balloy, D. (2013). Braking performance and influence of microstructure of advanced cast irons for heavy goods vehicle brake discs. Journal of Engineering Tribology, 227 (8), 930940.

[5] Crăciun, A. (2015). Evolution of materials for motor vehicles brake discs. ANNALS of Faculty Engineering Hunedoara - International Jurnal of Engineering, 13 (3), 149-154.

[6] Dubarry, M., Svoboda, V., Hwu, R., Liaw, B.Y. (2007). Capacity and power fading mechanism identification from a commercial cell evaluation. Journal of Power Sources, 165, 566-572.

[7] Fazio, O., Nacivet, S., Sinou, J. (2015). Reduction strategy for a brake system with local frictional nonlinearities - Application for the prediction of unstable vibration modes. Applied Acoustics, 91, 12-24.

[8] Fidlin, A., Bäuerle, S., Boy, F. (2015). Modelling of the gas induced fading of organic linings in dry clutches. Tribology International, 92, 559-566.

[9] Gill, A., Kadziński, A. (2015). The determination procedure of the onset of the object wear-out period based on monitoring of the empirical failure intensity function. Eksploatacja i Niezawodność - Maintenance and Reliability, 17 (2), 282-287.

[10] Glowacz, A. (2016). Fault diagnostics of acoustic signals of loaded synchronous motor using SMOFS25-EXPANDED and selected classifiers. Tehnicki Vjesnik-Technical Gazette, 23 (5), 1365-1372.

[11] Glowacz, A., Glowacz, Z. (2017). Diagnosis of stator faults of the single-phase induction motor using acoustic signals. Applied Acoustics, 117 (A), 20-27.

[12] Glowacz, A. (2016). Fault diagnostics of DC motor using acoustic signals and MSAF-RATIO30-EXPANDED. Archives of Electrical Engineering, 65 (4), 733-744.

[13] Gryboś, R. (2009). Machine Vibrations. Gliwice, Poland: Publishing House of Silesia University of Technology, 214.

[14] Grzes, P., Oliferuk, W., Adamowicz, A., Kochanowski, K., Wasilewski, P., Yevtushenko, A.A. (2016). The numerical-experimental scheme for the analysis of temperature field in a pad-disc braking system of a railway vehicle at single braking. International Communications in Heat and Mass Transfer, 75, 1-6.

[15] Hoguet, T. (2007). Brake tests at Bosch. Brüel \& Kjaer Magazine, 2, 22-24. 
[16] Kasem, H., Brunel, J.F., Dufrénoy, P., Siroux, M., Desmet, B. (2011). Thermal levels and subsurface damage induced by the occurrence of hot spots during high-energy braking. Wear, 270, 355-364.

[17] Kodeks UIC 541-3. Hdisc brake and its application. Conditions of brake pad permission for use. $7^{\text {th }}$ edition, June 2010, 10-24.

[18] Kruse, S., Tiedemann, M., Zeumer, B., Reuss, P., Hetzler, H., Hoffmann, N. (2015). The influence of joints of friction induced vibration in brake squeal. Journal of Sound and Vibration, 340, 239-252.

[19] Kumar, M., Boidin, X., Desplanques, Y., Bijwe, J. (2011). Influence of various metallic fillers in friction materials on hot-spot appearance during stop braking. Wear, 270, 371-381.

[20] Leszek, W. (2006). Selected methodological issues of empirical research. Institute of Maintenance Technology, Radom, Poland, 142-153.

[21] Mańczak, K. (1976). Techniques of Experiment Planning. Warsaw, Poland: WNT, 76-84.

[22] Neis, P.D., Ferreira, N.F., Lorini, F.J. (2011). Contribution to perform high temperature tests (fading) on a laboratory-scale tribometer. Wear, 271, 2660-2664.

[23] Paczkowska, M. (2016). The evaluation of the influence of laser treatment parameters on the type of thermal effects in the surface layer microstructure of gray irons. Optics and Laser Technology, 76, 143-148.

[24] Panier, S., Dufrénoy, P., Weichert, D. (2004). An experimental investigation of hot spots in railway disc brakes. Wear, 256, 764-773.

[25] Peveca, M., Oder, G., Potrč, I., Šraml, M. (2014). Elevated temperature low cycle fatigue of grey cast iron used for automotive brake discs. Engineering Failure Analysis, 42, 221-230.

[26] Polish Committee for Standardization. (2016). Railway - brake discs of rail vehicles - Part 3: Brake discs, properties of a disc brake and the friction pair, classification. PN-EN 14535-3, 12-16.

[27] Rudolph, M., Popp, K. (2001). Brake squeal. In Detection, Utilization and Avoidance of Nonlinear Dynamical Effects in Engineering Applications: Final Report of a Joint Research Project Sponsored by the German Federal Ministry of Education and Research. Shaker Verlag, 197-225.
[28] Sawczuk, W. (2016). Application of vibroacoustic diagnostics in the evaluation of wear of friction pads in a railway disc brake. Maintenance and Reliability, 18 (4), 565-571.

[29] Sawczuk, W. (2015). Application of selected frequency characteristics of vibration signal for the evaluation of the braking process for railway disc brake. Diagnostyka - Applied Structural Health, Usage and Condition Monitoring, 16 (3), 33-38.

[30] Sawczuk, W., Szymanski, G.M. (2016). Diagnostics of the railway friction disc brake based on the analysis of the vibration signals in terms of resonant frequency. Archive of Applied Mechanics, 86, 1-15.

[31] Segal, L. (1999). Diagnostic method for vehicle brake. NDT\&E International, 32, 369-373.

[32] Szymanski, G.M., Josko, M., Tomaszewski, F., Filipiak, R. (2015). Application of time-frequency analysis to the evaluation of the condition of car suspension. Mechanical System and Signal Processing, 58-59, 298-308.

[33] Szymanski, G.M., Josko, M., Tomaszewski, F. (2016). Diagnostics of automatic compensators of valve clearance in combustion engine with the use of vibration signal. Mechanical System and Signal Processing, 68-69, 479-490.

[34] Ścieszka, S.F. (1998). Friction Brakes. Material, Design and Tribological Issues. Publishing House Gliwice-Radom, Poland, 106-110.

[35] Triches, M., Samir, N.Y., Jordan, R. (2008). Analysis of brake squeal noise using finite element method. A parametric study. Applied Acoustics, 69, 147-162.

[36] Wirth, X. (1998). Improving the performance of disc brakes on high-speed rail vehicles with a novel types of brake pad: Isobar. RTR, 1, 24-29.

[37] Żółtowski, B., Lukasiewicz, M. (2012). Vibration Diagnostics of Machines. WNT Radom, Poland, 113115.

Received December 02, 2016. Accepted May 16, 2017. 